\title{
Development of a Simple Pretreatment Immunoassay Based on an Organic Solvent-Tolerant Nanobody for the Detection of Carbofuran in Vegetable and Fruit Samples
}

\author{
Jin-ru Zhang ${ }^{1}$, Yu Wang ${ }^{2}$, Jie-xian Dong ${ }^{3,4}$, Jin-yi Yang ${ }^{1}$, Yu-qi Zhang ${ }^{1}$, Feng Wang ${ }^{1}$, Rui Si ${ }^{1}$, \\ Zhen-lin $X u^{1, *(\mathbb{D})}$, Hong Wang ${ }^{1, *}$, Zhi-li Xiao ${ }^{1}$ and Yu-dong Shen ${ }^{1}$ \\ 1 Guangdong Provincial Key Laboratory of Food Quality and Safety, National-Local Joint Engineering \\ Research Center for Processing and Safety Control of Livestock and Poultry Products, College of Food \\ Science, South China Agricultural University, Guangzhou 510642, China; lovezjr0815@163.com (J.-r.Z.); \\ yjy361@163.com (J.-y.Y.); timzhang@stu.scau.edu.cn (Y.-q.Z.); wangfg024@163.com (F.W.); \\ huanongxiaosi@163.com (R.S.); scau_xzl@163.com (Z.-1.X.); shenyudong@scau.edu.cn (Y.-d.S.) \\ 2 Guangzhou Institute of Food Inspection, Guangzhou 510080, China; xxwangyu@163.com \\ 3 Department of Entomology and Nematology and UCD Comprehensive Cancer Center, University of \\ California, Davis, CA 95616, USA; jxdong@ucdavis.edu \\ 4 Neurobiology, Physiology \& Behavior, University of California, Davis, CA 95616, USA \\ * Correspondence: jallent@163.com (Z.-1.X.); gzwhongd@163.com (H.W.); Tel.: +86-20-85283448 (H.W.); \\ Fax: +86-20-85280270 (H.W.)
}

Received: 21 September 2019; Accepted: 4 October 2019; Published: 7 October 2019

\begin{abstract}
Nanobodies are one-tenth the size of conventional antibodies and are naturally obtained from the atypical heavy-chain-only antibodies present in camelids. Their small size, high solubility, high stability, and strong resilience to organic solvents facilitate their use as novel analytical reagents in immunochemistry. In this study, specific nanobodies against pesticide carbofuran were isolated and characterized from an immunized library via phage display platform. We further established an indirect competitive enzyme-linked immunosorbent assay (ELISA) using nanobody Nb316 to detect carbofuran in vegetable and fruit samples. The results showed a half-maximal inhibitory concentration $\left(\mathrm{IC}_{50}\right)$ of $7.27 \mathrm{ng} / \mathrm{mL}$ and a detection limit of $0.65 \mathrm{ng} / \mathrm{mL}$. A simplified sample pretreatment procedure omitting the evaporation of organic solvent was used. The averaged recovery rate of spiked samples ranged between $82.3 \%$ and $103.9 \%$, which correlated with that of standard UPLC-MS/MS method. In conclusion, a nanobody with high specificity for carbofuran was characterized, and a nanobody-based sensitive immunoassay for simple and rapid detection of carbofuran in real samples was validated.
\end{abstract}

Keywords: carbofuran; nanobody; enzyme-linked immunosorbent assay

\section{Introduction}

Carbofuran is a broad-spectrum insecticide widely used in a variety of agricultural crops to shorten the crop growth period and increase crop yields [1]. Due to its high solubility, carbofuran is easily absorbed by plant roots and transported to various plant organs, especially the edge of leaves [2]. However, carbofuran is highly toxic [3], and its use in agricultural products poses a potential hazard for human health and the environment [4]. The maximum residue limit (MRL) for carbofuran has been established under different legislations worldwide. For example, in the case of Chinese cabbages, cucumbers, and oranges, the MRL is $0.02 \mathrm{mg} / \mathrm{kg}$ in China. Therefore, it is necessary to detect carbofuran with high sensitivity and strong specificity. 
In recent years, many methods for the detection of carbofuran residues have been developed, such as gas chromatography, high-performance liquid chromatography, fluorescence detection, and immunochemical methods [5-9]. Enzyme-linked immunosorbent assay (ELISA) is a rapid technique for the detection of pesticide residues because of its sensitivity and high-throughput screening ability [10]. Most of the studies used polyclonal or monoclonal antibodies to develop ELISAs.

In 1993, Hamers-Casterman et al. identified naturally occurring heavy-chain-only antibodies in camelids, with variable regions representing antigen-binding pockets [11,12]. Single variable domains of heavy chain antibodies, also known as nanobodies, can be easily obtained from phage display libraries, which are not affected by the heavy/light chain shuffling [13]. Nanobody is advantageous compared with other recombinant antibody fragments in terms of high thermal stability, strong resilience against organic solvents, ease of genetic manipulation, and ease of expression in various expression systems, and is therefore an emerging reagent for use in immunoassay [14,15]. Nanobody-based ELISA methods for the detection of low-molecular-weight contaminants, such as aflatoxin B1 [16], microcystin-LR [17], triazophos [18], parathion [19], fipronil [20], and carbaryl [21] have been published. Carbofuran is an organic chemical, and most of the reported immunoassays involve complex pretreatment (extraction by organic solvent and blown dry by nitrogen). Due to the high organic solvent resistance, nanobody-based immunoassays facilitate rapid and simple monitoring of pesticides in vegetables and fruit samples.

In this study, we aimed to isolate nanobodies specifically recognize carbofuran from a Bactrian camel (Camelus bactrianus) immunized library. The nanobodies were carefully characterized and the optimal nanobody was selected to develop a competitive indirect ELISA. Finally, the presented immunoassay results were validated via comparison with UPLC-MS/MS analysis to spike vegetable and fruit samples.

\section{Materials and Methods}

\subsection{Materials and Reagents}

The haptens 4-[[(2,3-dihydro-2,2-dimethyl-7-benzofuranyloxy) carbonyl]-amino] butanoic acid (BFNB) was previously synthesized in the laboratory [22]. Carbofuran pesticide and its structural analogues were purchased from Hua Xin Bio. Co. Ltd. (Tianjin, China). Keyhole limpet hemocyanin (KLH), ovalbumin (OVA), and Freund's adjuvant were obtained from Sigma-Aldrich (St. Louis, MO, USA). The TRIzol reagent was purchased from Thermo Fisher Scientific (Shanghai, China). The first strand cDNA synthesis kit was obtained from TaKaRa (Dalian, China). Gel extraction and PCR purification kits were purchased from QIAGEN (Dusseldorf, Germany). Helper phage M13K07, SfiI restriction enzymes, and T4 DNA ligase were purchased from New England Biolabs (Beijing, China). The anti-HA tag antibody (HRP) was obtained from NOVUS Biologicals (Shanghai, China). Primary secondary amine (PSA), graphitized carbon black (GCB), C18 sorbents, and PestiCarb (PC) were purchased from Biocomma Limited (Shenzhen, China).

\subsection{Construction of Phage Display Nanobody Library}

A three-year-old Bactrian camel was immunized subcutaneously with $500 \mu \mathrm{g}$ of BFNB-KLH and Freund's adjuvant mixture biweekly. The immunogen BFNB-KLH and coating antigen BFNB-OVA were prepared using the active ester method. One week after the fifth immunization, $100 \mathrm{~mL}$ of peripheral blood was collected to complete lymphocyte isolation and total RNA extraction. The cDNA was synthesized using the TaKaRa First Strand RT-PCR Kit. The VHH genes were amplified by two-step nested PCR using the following primers: CALL001 (5'GTCCTGGCTGC TCTTCTACAAGG-3') and CALL002 (5'-GGTACGTGCTG TTGAACTGTTCC-3') for the first step; Sfi-Fr1 (5'-ACTGGCCCAGGCGGCCGAGGTGCAGCTGSWGSAKTCKG-3') and Sfi-Fr4 (5'-ACTGG CCGGCCTGGCCTGAGGAGACGGTGACCWGGGTC-3') in the second step [23]. The VHH genes were ligated into the pComb3Xss phagemid vector and then electroporated into the competent ER2738 cells. All cells were cultured on LB plates (containing $100 \mu \mathrm{g} / \mathrm{mL}$ ampicillin and $50 \mu \mathrm{g} / \mathrm{mL}$ 
tetracycline) overnight and then collected. After the infection of helper phage M13K07, the phage library was precipitated with PEG8000/ $\mathrm{NaCl}(2.5 \mathrm{M} \mathrm{NaCl}, 25 \mathrm{mM}$ PEG8000) and filtered through a $0.22 \mu \mathrm{m}$ membrane.

\subsection{Selection and Identification of Anti-Carbofuran Phage Clones}

The library was subjected to four rounds of panning on 96-well microtiter plates. For the first round, two wells of ELISA plate were coated with $10 \mu \mathrm{g} / \mathrm{mL}$ BFNB-OVA antigen (100 $\mu \mathrm{L}$ each) in PBS $\left(137 \mathrm{mM} \mathrm{NaCl}, 2.7 \mathrm{mM} \mathrm{KCl}, 4.3 \mathrm{mM} \mathrm{Na}_{2} \mathrm{HPO}_{4}\right.$, and $1.4 \mathrm{mM} \mathrm{KH}_{2} \mathrm{PO}_{4}$ ) via overnight incubation at $37^{\circ} \mathrm{C}$. Next day, the wells were blocked with $3 \%$ BSA for $2 \mathrm{~h}$ at $37^{\circ} \mathrm{C}$. The phage library was depleted with $2 \% \mathrm{KLH}, \mathrm{BSA}$, and OVA, and incubated at $37^{\circ} \mathrm{C}$ for $1 \mathrm{~h}$. The unbound phage was transferred to the BFNB-OVA well (100 $\mu \mathrm{L}$ per well) and shaken for $1 \mathrm{~h}$ at $37^{\circ} \mathrm{C}$. After washing the plate five times with PBST (PBS containing 0.5\% Tween) and 10 times with PBS, the bound phages were competitively eluted with $2 \mu \mathrm{g} / \mathrm{mL}$ carbofuran solution in PBS (100 $\mu \mathrm{L}$ per well) for $1 \mathrm{~h}$ shaken at $37^{\circ} \mathrm{C}$. Eluates (10 $\mu \mathrm{L}$ each) were diluted to calculate the panning output titer by plating on $\mathrm{LB}(100 \mathrm{mg} / \mathrm{mL}$ ampicillin, $50 \mathrm{mg} / \mathrm{mL}$ tetracycline), and $180 \mu \mathrm{L}$ of remaining samples were amplified for the next round of panning. A total of four rounds of panning were carried out. For the second, third, and fourth round, the plate was coated with BFNB-OVA at $5,1,0.2 \mu \mathrm{g} / \mathrm{mL}$ and the concentration of carbofuran for competitive elution was 1, $0.5,0.25 \mathrm{ng} / \mathrm{mL}$, respectively. After washing 10 times with PBST each round, the wells in second and fourth round were blocked with $1 \%$ gelatin instead of $3 \%$ BSA.

To determine the binding activity of clones against carbofuran, 190 clones were selected from the output plates in the third and fourth rounds, and induced by IPTG in deep well plates with LB medium containing $100 \mu \mathrm{g} / \mathrm{mL}$ ampicillin. The supernatant medium was used for indirect competitive ELISA detection after centrifugation at $3000 \mathrm{rpm}$ for $20 \mathrm{~min}$. ELISA plate were coated with $1 \mu \mathrm{g} / \mathrm{mL}$ BFNB-OVA antigen (100 $\mu \mathrm{L}$ each) and were blocked with 3\% BSA. All clones with significant inhibition rates (with $1 \mu \mathrm{g} / \mathrm{mL}$ carbofuran) clones were selected as positive clones and sequenced.

\subsection{Expression and Purification of Nanobody Protein}

The plasmid that specifically recognizes carbofuran was extracted from the ER2738 clone and was transformed into BL21(DE3)-competent cells by heat shock $\left(42{ }^{\circ} \mathrm{C}, 90 \mathrm{~s}\right)$. After sequencing and identification, a single clone was picked and grown in $10 \mathrm{~mL}$ of $\mathrm{LB}$ medium (100 $\mathrm{mg} / \mathrm{mL}$ ampicillin) overnight. The next day, $10 \mathrm{~mL}$ of the overnight culture was added to $1 \mathrm{~L}$ of $\mathrm{LB}$ (100 $\mathrm{mg} / \mathrm{mL}$ ampicillin) and shaken until the $\mathrm{OD}_{600}$ reached 0.6-0.8. IPTG was added at a final concentration of $1 \mathrm{mM}$ to induce the expression of nanobody protein with shaking at $250 \mathrm{rpm}$ overnight at $37^{\circ} \mathrm{C}$. Cell pellets were harvested after centrifugation at $12,000 \times g$ for $20 \mathrm{~min}$. The soluble nanobody protein was isolated from the cells via freezing and thawing method and sucrose osmotic pressure method (destroy cell wall with high osmotic pressure solution ( $300 \mathrm{mM}$ Tris, $0.65 \mathrm{mM}$ EDTA, $0.5 \mathrm{M}$ sucrose)), and purified using a gravity column packed with $1 \mathrm{~mL}$ of Ni-NTA resin [24]. The nanobody proteins were obtained via elution with imidazole using an increasing concentration gradient (10,20, and $50 \mathrm{mM}$ ), and dialyzed five times with PBS. After purification, the nanobody protein was characterized via SDS-PAGE and Western blot (anti-HA tag antibody (HRP)), and the concentration was determined using a NanoDrop 2000C system.

\subsection{Stability Analysis of Anti-Carbofuran Nanobody}

The stability of the nanobody at different temperatures was evaluated. The nanobody was diluted to the working concentration $(4 \mu \mathrm{g} / \mathrm{mL})$ and divided into seven equal portions. It was transferred to a water bath at $20,35,50,65,80$, and $95^{\circ} \mathrm{C}$ for $5 \mathrm{~min}$. It was also placed in a $95^{\circ} \mathrm{C}$ water bath, and heated for 10, 20, 30, 40, 50, and $60 \mathrm{~min}$. The binding activity of the nanobody to the antigen was measured by ELISA. The activity of the unheated nanobody to bind to the antigen was taken as $100 \%$.

The tolerance of the nanobody to different organic solvents and the same organic solvent at different concentrations was evaluated. Methanol and acetonitrile are the common solvents used 
for carbofuran extraction and were therefore selected to evaluate the organic solvent tolerance of nanobodies. The nanobody was diluted to the same working concentration using different solvent solutions with different concentrations (10\%, 20\%, 40\%, 60\%, and 80\%) of methanol and acetonitrile. The binding activity of the antibody to the antigen was determined by ELISA. The antigen-binding activity of the antibody diluted without the organic solvent to bind to the antigen was $100 \%$.

\subsection{Nanobody-Based Indirect Competitive ELISA}

A 96-well plate (100 $\mu \mathrm{L}$ per well) with $1 \mu \mathrm{g} / \mathrm{mL}$ of BFNB-OVA in PBS was coated by overnight incubation at $37^{\circ} \mathrm{C}$. The next day, the plate was blocked with $1 \%$ fish collagen $(120 \mu \mathrm{L}$ per well $)$ at $37^{\circ} \mathrm{C}$ for $2 \mathrm{~h}$. Each well was treated with $50 \mu \mathrm{L}$ of a gradient dilution of carbofuran and $50 \mu \mathrm{L}$ of $4 \mu \mathrm{g} / \mathrm{mL}$ nanobody. The plate was incubated at $37^{\circ} \mathrm{C}$ for $1 \mathrm{~h}$. The plate was washed five times with PBST and exposed to $100 \mu \mathrm{L}$ of anti-HA-HRP antibody in PBS followed by incubation for $40 \mathrm{~min}$ at $37^{\circ} \mathrm{C}$. After washing the plate five times, $100 \mu \mathrm{L}$ of TMB $\left(3,3^{\prime}, 5,5^{\prime}\right.$-Tetramethylbenzidine $)$ chromogenic solution was added, and the reaction was terminated after $10 \mathrm{~min}$ by adding $50 \mu \mathrm{L}$ of $10 \% \mathrm{H}_{2} \mathrm{SO}_{4}$. The absorbance at $450 \mathrm{~nm}$ was measured using a microplate reader, and the standard curve was fitted with a four-parameter fitting module of Origin 9.0. The half maximal inhibitory concentration $\left(\mathrm{IC}_{50}\right)$ and limit of detection (LOD) denote the carbofuran concentrations at $50 \%$ and $10 \%$ inhibition, respectively. The cross-reaction rate was calculated as follows: $\mathrm{CR}(\%)=\mathrm{IC}_{50}$ (carbofuran, $\left.\mathrm{ng} / \mathrm{mL}\right) / \mathrm{IC} 50$ (carbofuran analogues, $\mathrm{ng} / \mathrm{mL}) \times 100$.

\subsection{Immunoassay Validation}

Samples of fresh Chinese cabbage, cucumber, and orange were obtained from the local market. The samples are simply cleaned and smashed with a homogenizer. The quick, easy, cheap, effective, rugged, and safe (Quechers) EN15662 method was used to pretreat the samples [25]. Briefly, $10 \mathrm{~g}$ of a finely crushed vegetable sample (accurate to 0.01) was weighed in a tube and mixed with a standard solution of $0.1 \mathrm{~mL}(10,20$, and $50 \mathrm{ng} / \mathrm{g})$ carbofuran pesticide prepared using methanol. After the addition of $10 \mathrm{~mL}$ acetonitrile, the tube was vortexed for $1 \mathrm{~min}$. An extract salt pack (containing $4 \mathrm{~g}$ magnesium sulfate, $1 \mathrm{~g}$ sodium chloride, $1 \mathrm{~g}$ sodium citrate, and $0.5 \mathrm{~g}$ disodium hydrogen citrate) was added, shaken for $1 \mathrm{~min}$, and centrifuged at $4000 \mathrm{rpm}$ for $5 \mathrm{~min}$. A $6 \mathrm{~mL}$ aliquot of the supernatant was transferred into a clean tube containing $150 \mathrm{mg}$ PSA, $45 \mathrm{mg}$ GCB, and $900 \mathrm{mg}$ magnesium sulfate, vortexed for $1 \mathrm{~min}$, and centrifuged at $4000 \mathrm{rpm}$ for $5 \mathrm{~min}$. To eliminate the matrix effect, the supernatant was directly diluted five times with PBS buffer and passed through a $0.22 \mu \mathrm{m}$ filter to obtain the sample. The carbofuran content and addition recovery were determined using the indirect competitive ELISA (ic-ELISA). The recovery rate was expected to remain within a relatively stable and narrow interval $(80 \%-120 \%)$. The addition recovery rate $(\mathrm{R}, \%)$ and the coefficient of variation $(\mathrm{CV}, \%)$ were calculated according to the following formula: Addition recovery rate $(\%)=$ measured value/added value $\times$ $100 \%$; coefficient of variation $(\%)=$ standard error $(\mathrm{SD}) /$ average value $\times 100 \%$. The UPLC-MS/MS method was used to verify the results of the ic-ELISA-based nanobody detection. The conditions were used as follows: mobile phase A consisted of $5 \mathrm{mmol} / \mathrm{L}$ ammonium formate and $0.1 \%$ formic acid in methanol, and mobile phase B consisted of $5 \mathrm{mmol} / \mathrm{L}$ ammonium formate and $0.1 \%$ formic acid in water. The gradient elution was 0-9 $\mathrm{min}, 90 \% \mathrm{~B}-50 \% \mathrm{~B} ; 9-20 \mathrm{~min}, 50 \% \mathrm{~B}-35 \% \mathrm{~B} ; 20-29 \mathrm{~min}, 35 \% \mathrm{~B}-0$; and $30-34 \mathrm{~min}, 0-90 \% \mathrm{~B}$. The flow rate of the mobile phase was $0.3 \mathrm{~mL} / \mathrm{min}$, and $10 \mu \mathrm{L}$ of each sample was injected into the UPLC system. 


\section{Results and Discussion}

\subsection{Library Construction and Selection of Anti-Carbofuran Phage Clones}

A phage display nanobody library was obtained via genetic recombination and the calculated size of the library was $1.06 \times 10^{8} \mathrm{cfu} / \mathrm{mL}$. Twenty-five clones that randomly picked from LB plates were sequenced, and the diversity of library sequence was $100 \%$. After rescuing with $10^{12} \mathrm{pfu} / \mathrm{mL}$ helper phage M13K07, the phage display nanobody library titer was $10^{11} \mathrm{pfu} / \mathrm{mL}$. After the second round, the phage output increased from $10^{5}$ to $10^{7} \mathrm{pfu} / \mathrm{mL}$, indicating significant enrichment of specific phage clones binding to the coated antigen BFNB-OVA. The third and fourth output was selected to identify specific phage clones. The results showed that $80 \%$ of all the clones bound to BFNB-OVA and differed in their binding activity to carbofuran, indicating efficient experimental screening. All positive clones with inhibition rates (with $1 \mu \mathrm{g} / \mathrm{mL}$ carbofuran) greater than $50 \%$ were sequenced, and nine groups of clones were classified based on the complementarity determining region 3 (CDR3). Clones with the highest inhibition rate in each group were selected: Nb309 (393 bp), Nb316 (393 bp), Nb328 (375 bp), Nb391 (393 bp), Nb393 (372 bp), Nb415 (372 bp), Nb438 (372 bp), Nb480 (384 bp), and Nb489 (366 bp). The results of ic-ELISA (Figure 1) showed that the inhibition rates of nine clones with $1 \mu \mathrm{g} / \mathrm{mL}$ carbofuran were $91.0 \%, 95.3 \%, 82.0 \%, 94.1 \%, 89.3 \%, 94.2 \%, 92.4 \%, 91.3 \%$, and $65.1 \%$, respectively. Nine clone sequences were aligned, and the sequence similarity of the framework regions in the nine clones was extremely high and very conserved (Figure 2). The CDRs, especially CDR3 (15-24 amino acids), showed rich diversity. Among these nine clones, Nb316 showed the highest inhibition rate and was used for subsequent studies.

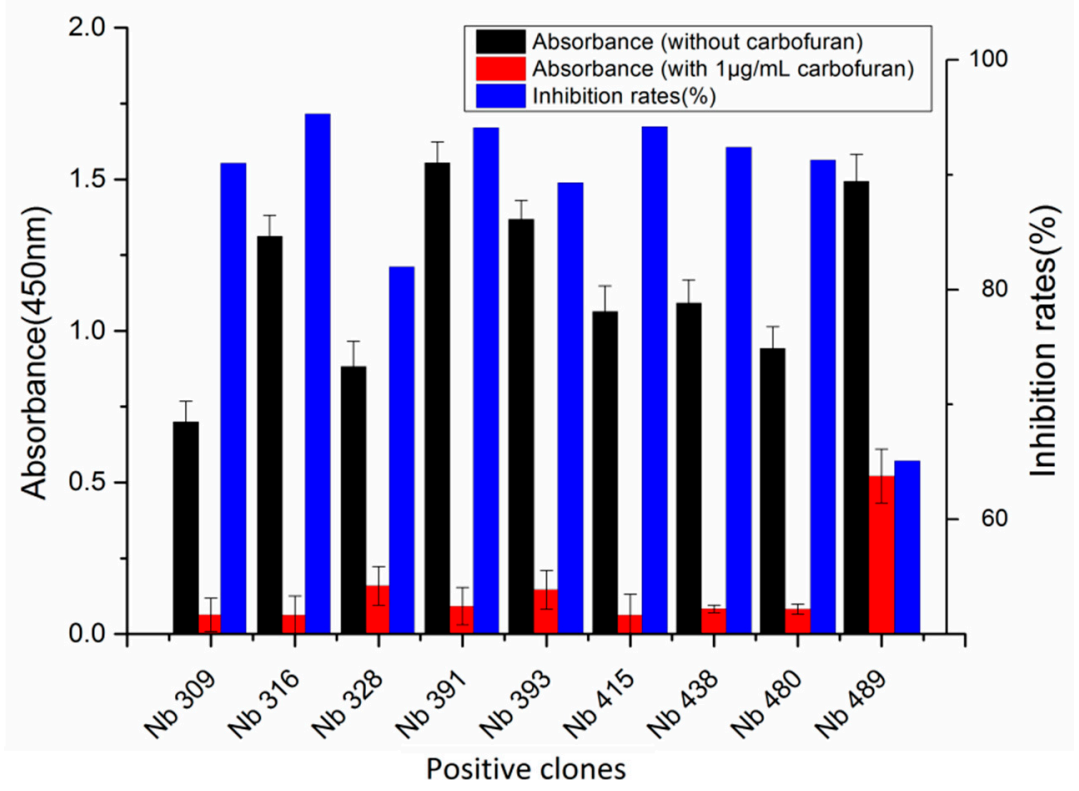

Figure 1. Nine phage clones binding to carbofuran selected and identified by ic-ELISA. Inhibition rate = (absorbance at $450 \mathrm{~nm}$ without carbofuran —absorbance at $450 \mathrm{~nm}$ with $1 \mu \mathrm{g} / \mathrm{mL}$ carbofuran)/absorbance at $450 \mathrm{~nm}$ without carbofuran. Nb316 showed the highest inhibition rate for carbofuran. 


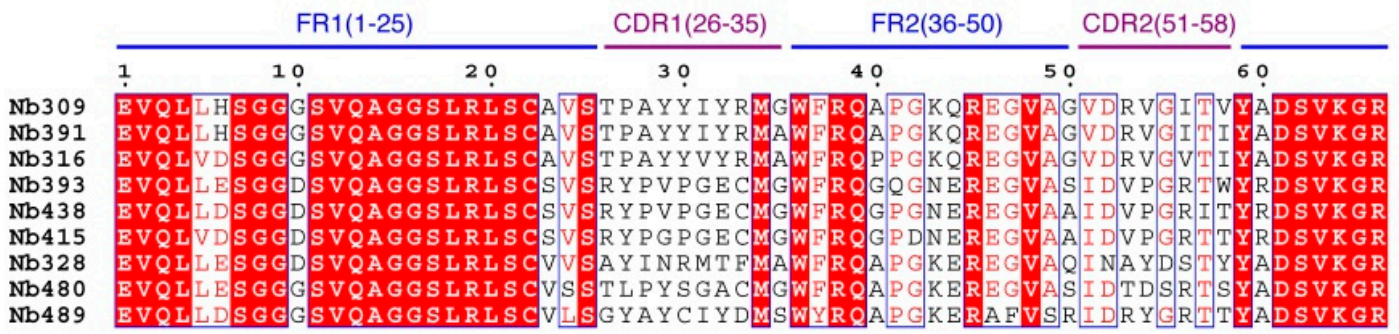

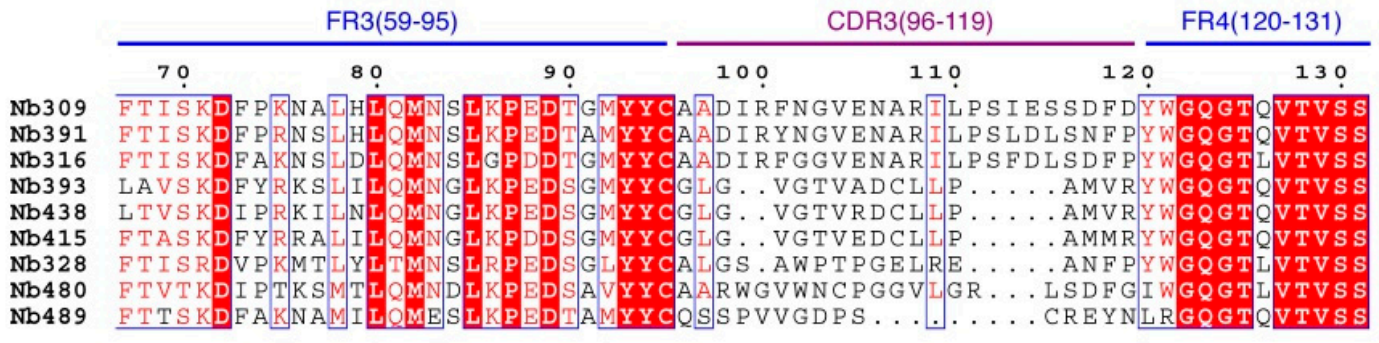

Figure 2. Sequence alignment of nine positive clones.

\subsection{Preparation and Stability Analysis of Anti-Carbofuran Nanobody}

Nanobody Nb316 was expressed in Escherichia coli BL21 (DE3) and then purified (Figure 3). The protein yield was about $2 \mathrm{mg} / \mathrm{L}$ and the purity was higher than $90 \%$. The stability of nanobody was evaluated by the antigen-binding activity (the binding ability between antigen and antibody) at high temperature and in the presence of high concentration of organic solvents. After incubation for 5 min at different temperatures, the binding activity of $\mathrm{Nb} 316$ was not substantially reduced. Moreover, the binding activity remained at about $100 \%$ during incubation for $1 \mathrm{~h}$ at $95^{\circ} \mathrm{C}$ (Figure $4 \mathrm{~A}, \mathrm{~B}$ ). The high thermal stability of nanobodies may be attributed to four hallmark nanobody-specific amino acids, Phe, Glx, Arg, and Gly in framework region 2 (FR2), which increase the hydrophilicity of the antibody and stabilize nanobodies [26,27]. In addition, the heat resistance of nanobodies is also related to reversible refolding, as well as the amount and location of disulfide bonds [28-31].
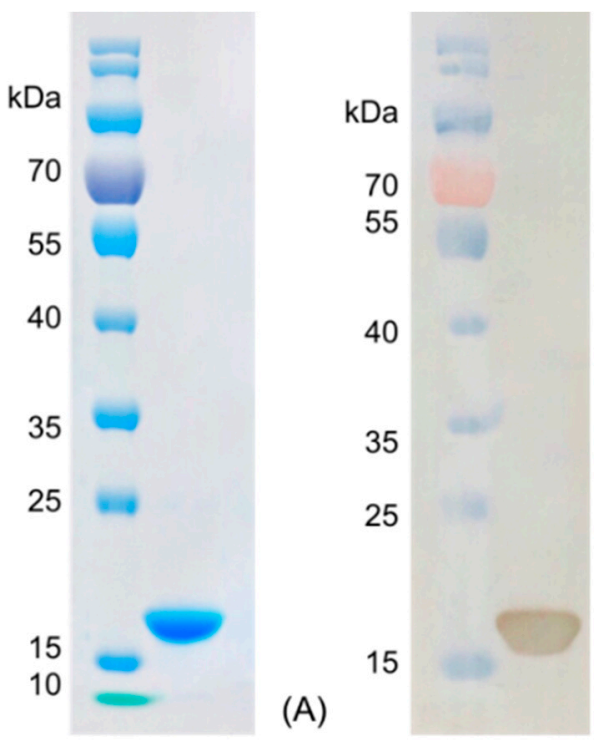

(B)

Figure 3. Characterization of nanobody Nb316 by SDS-PAGE and Western blotting. (A) SDS-PAGE: marker and purified Nb316. (B) Western blotting: marker and purified Nb316. 

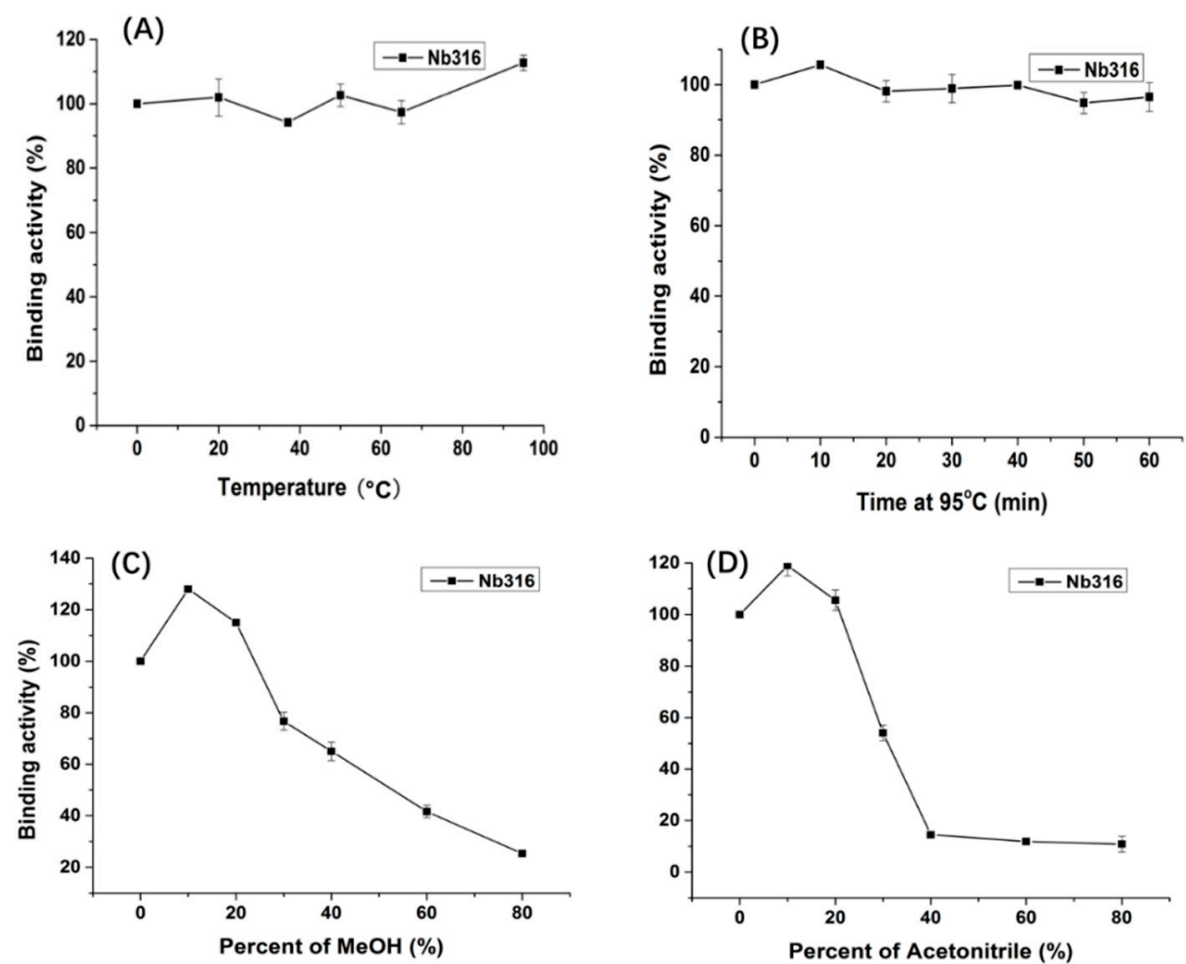

Figure 4. Thermostability and organic solvents tolerance of $\mathrm{Nb} 316$ by indirect ELISA based on the antigen BFNB-OVA and anti-HA-HRP antibody. (A) Nb316 (1 mg/mL) was incubated at 20, 35, 50, 65, 80 , and $95^{\circ} \mathrm{C}$ for $5 \mathrm{~min}$; (B) $\mathrm{Nb3} 16(1 \mathrm{mg} / \mathrm{mL})$ was incubated at $95^{\circ} \mathrm{C}$ for $10,20,30,40,50$, and $60 \mathrm{~min}$. A series concentration $(10 \%, 20 \%, 40 \%, 60 \%$, and $80 \%)$ of (C) $\mathrm{MeOH}$ and (D) acetonitrile was as the dilution reagents with $\mathrm{Nb316.}$

Immunoassays are usually carried out in aqueous solution, which is an ideal environment for antibodies. However, some environmental analytes, such as pesticides, are not easily dissolved in water, and sample extraction requires an organic solvent. Therefore, the high tolerance of antibody to organic solvents is extremely important. The binding activity of the nanobody Nb316 to the coating antigen is promoted in 10\% methanol and acetonitrile (Figure 4C,D). The nanobody still shows 50\% binding activity when the methanol concentration is $50 \%$ and the acetonitrile concentration is $30 \%$. Thus, nanobodies also exhibit high tolerance to high concentrations of methanol and acetonitrile. The excellent thermal stability and tolerance of nanobodies to organic solvents promoted the stability of nanobodies in actual test samples.

\subsection{Nanobody-Based Ic-ELISA}

An ic-ELISA method based on Nb316 for the detection of carbofuran was established. The coating antigen and nanobody concentration were optimized via checkerboard titration. The optimal concentration of coating antigen is $1 \mu \mathrm{g} / \mathrm{mL}$ and nanobody is $4 \mu \mathrm{g} / \mathrm{mL}$. As Figure 5 shows, the $\mathrm{IC}_{50}$ was $7.27 \pm 0.88 \mathrm{ng} / \mathrm{mL}$. The linear range varied from $1.44 \mathrm{ng} / \mathrm{mL}$ to $30.39 \mathrm{ng} / \mathrm{mL}$, and the detection limit was $0.65 \pm 0.24 \mathrm{ng} / \mathrm{mL}$.

The specificity of nanobody was determined by comparing with $\mathrm{IC}_{50}$ values of other standard curves of carbofuran structural analogs. The $\mathrm{IC}_{50}$ values ic-ELISA based on $\mathrm{Nb} 316$ to benfuracarb, fenobucarb, carbosulfan, 3-hydroxycarbofuran, and isoprocarb was 142.51, 204.6, 280.93, 366.05, and $1351.82 \mathrm{ng} / \mathrm{mL}$, with cross-reactivities (CRs) of 5.1\%, 3.5\%, 2.6\%, 2.0\%, and $0.5 \%$, respectively (Table 1). The CRs of seven other structural analogs were all below $0.1 \%$. The nanobody Nb316 showed good sensitivity and specificity for carbofuran recognition. Compared with the monoclonal antibody-based ELISA ( $\mathrm{IC}_{50}$ value, $18.49 \mathrm{ng} / \mathrm{mL}$ ) previously established by Yang et al. in this laboratory, 
the method adopted in this study was more sensitive [22]. Also, Zhu et al. used hapten BFNP to develop a direct competitive enzyme-linked immunoassay for carbofuran, and the $\mathrm{IC}_{50}$ value was $36.1 \mathrm{ng} / \mathrm{mL}$ [32]. The $\mathrm{IC}_{50}$ of the method of Moreno et al. is $0.74 \mathrm{ng} / \mathrm{mL}$, but the method is a competitive heterologous ELISA in the antibody-coated format [33].

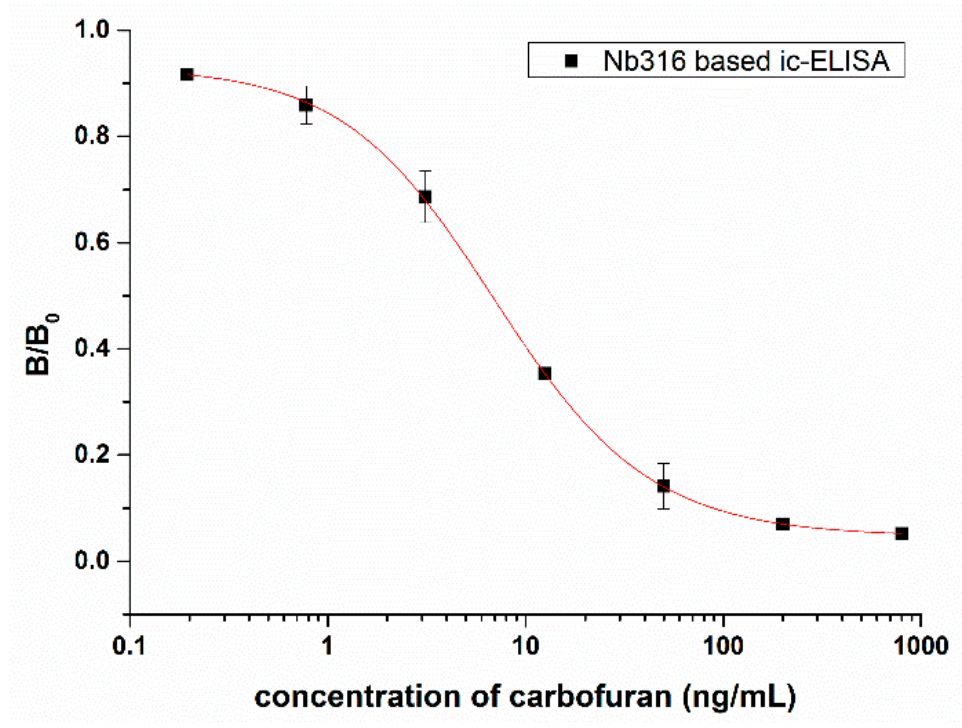

Figure 5. Standard competitive inhibition curve for carbofuran analysis under the optimized conditions.

Table 1. Cross-reactivity of nanobody Nb316 with carbofuran structural analogues.

\begin{tabular}{|c|c|c|c|}
\hline Analogues & Molecular Structural & $\mathrm{IC}_{50}(\mathrm{ng} / \mathrm{mL})$ & Cross-Reactivity (\%) \\
\hline Carbofuran & & 7.27 & 100 \\
\hline Benfuracarb & & 142.51 & 5.1 \\
\hline Fenobucarb & & 204.6 & 3.5 \\
\hline Carbosulfan & & 280.93 & 2.6 \\
\hline 3-Hydroxycarbofuran & & 366.05 & 2.0 \\
\hline
\end{tabular}


Table 1. Cont.

Analogues

\subsection{Sample Analysis by ic-ELISA and UPLC-MS/MS}

Vegetable and fruit samples were extracted with acetonitrile. The matrix effect was tested with different dilutions and it was found that the matrix effect could be eliminated with a five-fold PBS dilution. The ic-ELISA standard curve established with the five-fold blank sample extract was substantially identical to the standard curve established with $20 \%$ acetonitrile buffer (Figure 6). Vegetable and fruit samples spiked with different concentrations $(10,20$, and $50 \mathrm{ng} / \mathrm{g})$ of carbofuran were measured by ic-ELISA (Table 2). The average recovery of samples varied between $82.3 \%$ and $103.9 \%$ following the addition level. The coefficient of variation was within $10 \%$, which met the testing requirements of actual samples. To evaluate the accuracy of ic-ELISA method, the fortified samples were also validated by UPLC-MS/MS. The correlation coefficient between ic-ELISA and UPLC-MS/MS was 0.9913 (Figure 7). Overall, the pretreatment method omitting the evaporation step of organic solvent is feasible, and Nb316-based ic-ELISA method can be used for the detection of carbofuran in vegetables and fruits accurately and reproducibly. 


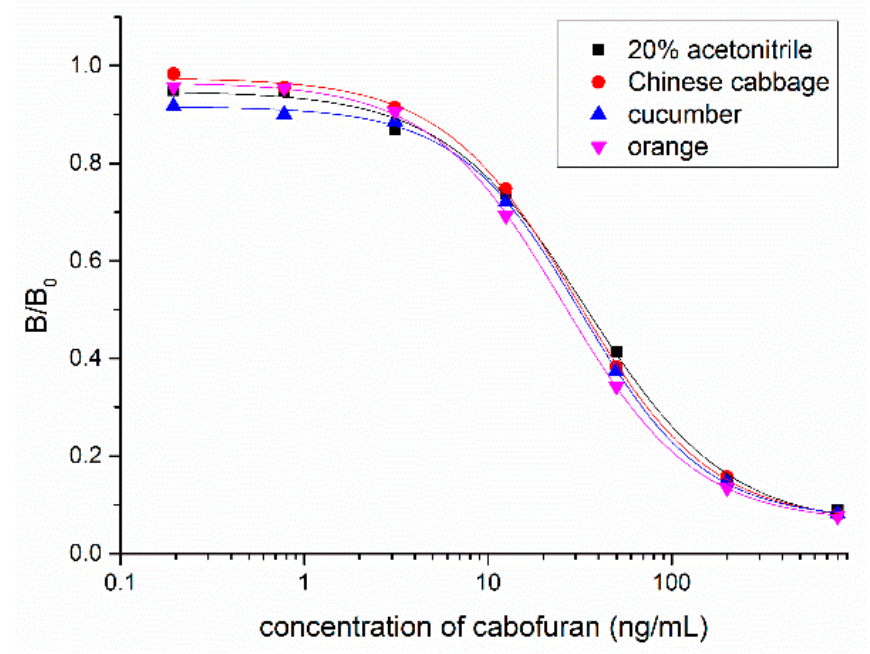

Figure 6. Matrix effects of Chinese cabbage, cucumber, and orange samples.

Table 2. Recovery analysis of carbofuran in Chinese cabbage, cucumber, and orange samples by ic-ELISA.

\begin{tabular}{cccccccccc}
\hline \multirow{2}{*}{$\begin{array}{c}\text { Added } \\
(\mathbf{m g} / \mathbf{k g})\end{array}$} & $\begin{array}{c}\text { Found } \pm \\
\text { SD } \\
(\mathbf{m g} / \mathbf{k g})\end{array}$ & $\begin{array}{c}\text { Recovery } \\
\mathbf{( \% )}\end{array}$ & $\begin{array}{c}\text { CV } \\
\mathbf{( \% )}\end{array}$ & $\begin{array}{c}\text { Found } \pm \\
\text { SD } \\
(\mathbf{m g} / \mathbf{k g})\end{array}$ & $\begin{array}{c}\text { Recovery } \\
\mathbf{( \% )}\end{array}$ & $\begin{array}{c}\text { CV } \\
\mathbf{( \% )}\end{array}$ & $\begin{array}{c}\text { Found } \pm \\
\text { SD } \\
(\mathbf{m g} / \mathbf{k g})\end{array}$ & $\begin{array}{c}\text { Recovery } \\
\mathbf{( \% )}\end{array}$ & $\begin{array}{c}\text { CV } \\
(\mathbf{\%})\end{array}$ \\
\hline 10 & $10.27 \pm 0.34$ & 102.7 & 3.33 & $9.73 \pm 0.24$ & 97.35 & 2.52 & $8.47 \pm 0.2$ & 84.74 & 2.35 \\
20 & $18.44 \pm 0.54$ & 92.25 & 2.61 & $20.45 \pm 0.31$ & 102.26 & 1.50 & $16.46 \pm 0.22$ & 82.31 & 1.21 \\
50 & $51.96 \pm 0.75$ & 103.92 & 1.44 & $46.24 \pm 0.51$ & 92.48 & 1.11 & $43.77 \pm 0.91$ & 87.54 & 20.76 \\
\hline
\end{tabular}

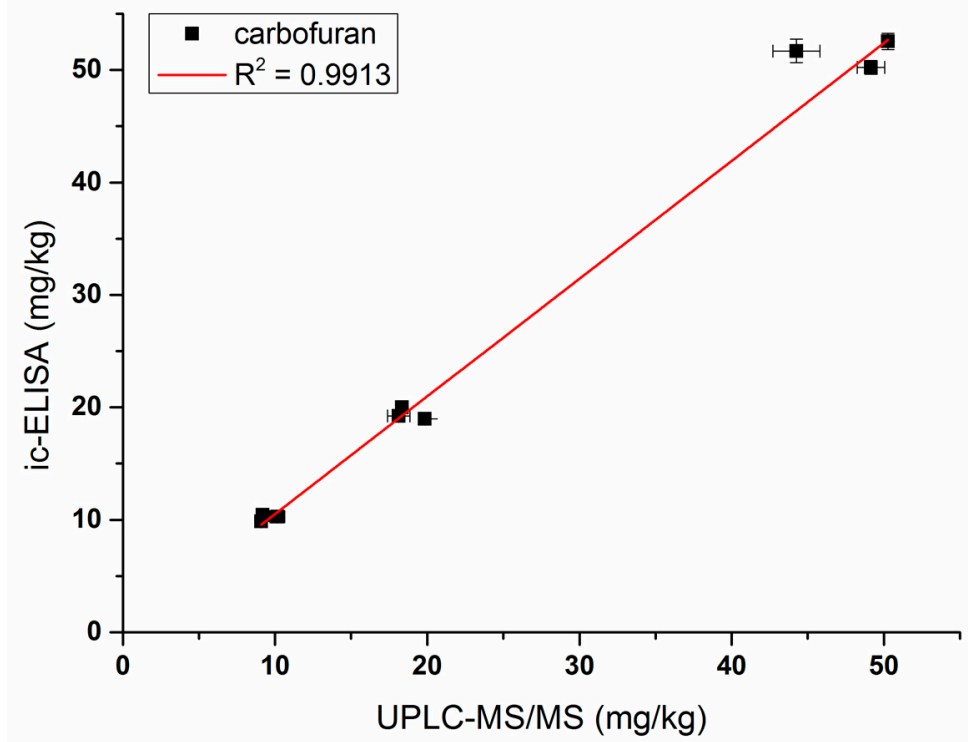

Figure 7. Correlations of analysis of samples spiked with carbofuran between Nb316-based ic-ELISA and UPLC-MS/MS.

\section{Conclusions}

A nanobody $\mathrm{Nb} 316$ specific for carbofuran with good thermal stability and high resistance to methanol and acetonitrile was isolated from the phage display library. Based on the nanobody, a competitive indirect ELISA was developed and used to determine carbofuran in vegetable and fruit samples. Simple pretreatment omitting evaporation step of organic solvent was used. The proposed immunoassay showed good sensitivity and specificity to carbofuran. The proposed methods validated 
by standard UPLC-MS/MS were accurate and reproducible. A nanobody-based immunoassay is an ideal screening tool for carbofuran monitoring due to its simplicity, rapidity, and cost-effectiveness.

Author Contributions: Conceptualization, J.-r.Z. and H.W.; Methodology, J.-r.Z., J.-x.D., and Y.-q.Z.; Resources, J.-y.Y. and R.S.; Data Curation, J.-r.Z., Y.W., and F.W.; Writing-Original Draft Preparation, J.-r.Z.; Writing-Review \& Editing, H.W. J.-x.D., and Z.-1.X. (Zhen-lin Xu); Supervision, H.W., Z.-l.X. (Zhi-li Xiao), and Y.-d.S.; Project Administration, H.W.

Funding: This work was supported by National Key R\&D Program of China (2016YFE0106000), Key Area R\&D Program of Guangdong Province (No. 2019B020211002), National Natural Science Foundation of China (31972157), Science and Technology Planning Project of Guangzhou City (201804020077), Science and Technology Planning Project of Guangdong Province (2018A050506072), Project Supported by Guangdong Province Universities and Colleges Pearl River Scholar Funded Scheme (2017) and International Cooperation Program of SCAU (2019SCAUGH03).

Conflicts of Interest: The authors declare no conflicts of interest.

\section{References}

1. Dai, Y.; Wang, T.; Hu, X.; Liu, S.; Zhang, M.; Wang, C. Highly sensitive microcantilever-based immunosensor for the detection of carbofuran in soil and vegetable samples. Food Chem. 2017, 229, 432-438. [CrossRef] [PubMed]

2. Liu, L.; Xu, D.; Hu, Y.; Liu, S.; Wei, H.; Zheng, J.; Wang, G.; Hu, X.; Wang, C. Construction of an impedimetric immunosensor for label-free detecting carbofuran residual in agricultural and environmental samples. Food Control 2015, 53, 72-80. [CrossRef]

3. Tien, C.; Huang, H.; Chen, C.S. Accessing the Carbofuran Degradation Ability of Cultures from Natural River Biofilms in Different Environments. CLEAN Soil Air Water 2017, 45, 1600380. [CrossRef]

4. Gupta, R.C. Carbofuran toxicity. J. Toxicol. Environ. Health 1994, 43, 383-418. [CrossRef] [PubMed]

5. Saraji, M.; Esteki, N. Analysis of carbamate pesticides in water samples using single-drop microextraction and gas chromatography-mass spectrometry. Anal. Bioanal. Chem. 2008, 391, 1091-1100. [CrossRef]

6. Carla, S.; Brett, H.; Ambrose, F.; James, K.J.; Jordi, M.E.; Yolanda, P. Liquid chromatography quadrupole time-of-flight mass spectrometry analysis of carbosulfan, carbofuran, 3-hydroxycarbofuran, and other metabolites in food. Anal. Chem. 2007, 79, 1492-1501.

7. Gui, W.; Jin, M.; Sun, L.; Guo, Y.; Zhu, G. Residues determination of carbofuran in vegetables based on sensitive time-resolved fluorescence immunoassay. Food Agric. Immunol. 2009, 20, 49-56. [CrossRef]

8. Bellemjid, N.; Iddar, A.; Moussaif, A.; Abbadi, N.E.; Mesfioui, A. Analysis of Carbamates Pesticides: Immunogical Technique by Local Development of Enzyme-linked Immuno-Sorbent Assay. J. Pharm. Pharmacol. 2018, 6, 395-402. [CrossRef]

9. Yang, J.Y.; Zhang, Y.; Wang, H.; Xu, Z.L.; Eremin, S.A.; Shen, Y.D.; Wu, Q.; Lei, H.T.; Sun, Y.M. Development of fluorescence polarisation immunoassay for carbofuran in food and environmental water samples. Food Agric. Immunol. 2015, 26, 340-355. [CrossRef]

10. Liu, A.; Anfossi, L.; Shen, L.; Li, C.; Wang, X. Non-competitive immunoassay for low-molecular-weight contaminant detection in food, feed and agricultural products: A mini-review. Trends Food Sci. Tech. 2018, 71, 181-187. [CrossRef]

11. Kim, H.; McCoy, M.R.; Majkova, Z.; Dechant, J.E.; Gee, S.J.; Tabares-da Rosa, S.; González-Sapienza, G.G.; Hammock, B.D. Isolation of Alpaca Anti-Hapten Heavy Chain Single Domain Antibodies for Development of Sensitive Immunoassay. Anal. Chem. 2012, 84, 1165-1171. [CrossRef] [PubMed]

12. Hamers-Casterman, C.; Atarhouch, T.; Muyldermans, S.; Robinson, G.; Hammers, C.; Songa, E.B.; Bendahman, N.; Hammers, R. Naturally occurring antibodies devoid of light chains. Nature 1993, 363, 446-448. [CrossRef] [PubMed]

13. Rossotti, M.A.; Pirez, M.; Gonzalez-Techera, A.; Cui, Y.; Bever, C.S.; Lee, K.S.S.; Morisseau, C.; Leizagoyen, C.; Gee, S.; Hammock, B.D.; et al. Method for Sorting and Pairwise Selection of Nanobodies for the Development of Highly Sensitive Sandwich Immunoassays. Anal. Chem. 2015, 87, 11907-11914. [CrossRef] [PubMed]

14. Bever, C.S.; Dong, J.; Vasylieva, N.; Barnych, B.; Cui, Y.; Xu, Z.; Hammock, B.D.; Gee, S.J. VHH antibodies: Emerging reagents for the analysis of environmental chemicals. Anal. Bioanal. Chem. 2016, 408, 5985-6002. [CrossRef] [PubMed] 
15. Sun, Z.; Duan, Z.; Liu, X.; Deng, X.; Tang, Z. Development of a Nanobody-Based Competitive Dot ELISA for Visual Screening of Ochratoxin A in Cereals. Food Anal. Methods 2017, 10, 3558-3564. [CrossRef]

16. Ren, W.; Li, Z.; Xu, Y.; Wan, D.; Barnych, B.; Li, Y.; Tu, Z.; He, Q.; Fu, J.; Hammock, B.D. One-Step Ultrasensitive Bioluminescent Enzyme Immunoassay Based on Nanobody/Nanoluciferase Fusion for Detection of Aflatoxin B1 in Cereal. J. Agric. Food Chem. 2019, 67, 5221-5229. [CrossRef]

17. Xu, C.; Yang, Y.; Liu, L.; Li, J.; Liu, X.; Zhang, X.; Liu, Y.; Zhang, C.; Liu, X. Microcystin-LR nanobody screening from an alpaca phage display nanobody library and its expression and application. Ecotoxicol. Environ. Saf. 2018, 151, 220-227. [CrossRef]

18. Wang, K.; Liu, Z.; Ding, G.; Li, J.; Vasylieva, N.; Li, Q.X.; Li, D.; Gee, S.J.; Hammock, B.D.; Xu, T. Development of a one-step immunoassay for triazophos using camel single-domain antibody-alkaline phosphatase fusion protein. Anal. Bioanal. Chem. 2019, 411, 1287-1295. [CrossRef]

19. Zhang, Y.; Xu, Z.; Wang, F.; Cai, J.; Dong, J.; Zhang, J.; Si, R.; Wang, C.; Wang, Y.; Shen, Y.; et al. Isolation of Bactrian Camel Single Domain Antibody for Parathion and Development of One-Step dc-FEIA Method Using VHH-Alkaline Phosphatase Fusion Protein. Anal. Chem. 2018, 90, 12886-12892. [CrossRef]

20. Wang, K.; Vasylieva, N.; Wan, D.; Eads, D.A.; Yang, J.; Tretten, T.; Barnych, B.; Li, J.; Li, Q.X.; Gee, S.J.; et al. Quantitative Detection of Fipronil and Fipronil-Sulfone in Sera of Black-Tailed Prairie Dogs and Rats after Oral Exposure to Fipronil by Camel Single-Domain Antibody-Based Immunoassays. Anal. Chem. 2019, 91, 1532-1540. [CrossRef]

21. Liu, Z.; Wang, K.; Wu, S.; Wang, Z.; Ding, G.; Hao, X.; Li, Q.X.; Li, J.; Gee, S.J.; Hammock, B.D. Development of a camelid variable domain of heavy chain antibody-based immunoassay for the detection of carbaryl in cereals. J. Sci. Food Agric. 2019, 99, 4383-4390. [CrossRef] [PubMed]

22. Yang, J.Y.; Wang, H.; Jiang, J.M.; Sun, Y.M.; Pan, K.; Lei, H.T.; Wu, Q.; Shen, Y.D.; Xiao, Z.L.; Xu, Z.L. Development of an enzyme-linked immuno-sorbent assay (ELISA) method for carbofuran residues. Molecules 2008, 13, 871-881. [CrossRef] [PubMed]

23. Ebrahimizadeh, W.; Mousavi Gargari, S.; Rajabibazl, M.; Safaee Ardekani, L.; Zare, H.; Bakherad, H. Isolation and characterization of protective anti-LPS nanobody against $V$. cholerae O1 recognizing Inaba and Ogawa serotypes. Appl. Microbiol. Biot. 2013, 97, 4457-4466. [CrossRef] [PubMed]

24. Olichon, A.; Schweizer, D.; Muyldermans, S.; Marco, A.D. Heating as a rapid purification method for recovering correctly-folded thermotolerant VH and VHH domains. BMC Biotechnol. 2007, 7, 7-14. [CrossRef] [PubMed]

25. Cieślik, E.; Sadowska-Rociek, A.; Ruiz, J.M.M.; Surma-Zadora, M. Evaluation of QuEChERS method for the determination of organochlorine pesticide residues in selected groups of fruits. Food Chem. 2011, 125, 773-778. [CrossRef]

26. Cécile, V.; Remy, L.; Dirk, S.; Sergio, M.R.; Serge, M.; Katja, C. General strategy to humanize a camelid single-domain antibody and identification of a universal humanized nanobody scaffold. J. Biol. Chem. 2009, $284,3273-3284$.

27. Muyldermans, S.; Atarhouch, T.; Saldanha, J.; Barbosa, J.A.R.G.; Hamers, R. Sequence and structure of $V_{H}$ domain from naturally occurring camel heavy chain immunoglobulins lacking light chains. Protein Eng. 1994, 7, 1129-1135. [CrossRef]

28. Pérez, J.M.J.; Renisio, J.G.; Prompers, J.J.; van Platerink, C.J.; Cambillau, C.; Darbon, H.; Frenken, L.G.J. Thermal Unfolding of a Llama Antibody Fragment: A Two-State Reversible Process. Biochemistry 2001, 40, 74-83. [CrossRef]

29. Akazawaogawa, Y.; Uegaki, K.; Hagihara, Y. The role of intra-domain disulfide bonds in heat-induced irreversible denaturation of camelid single domain VHH antibodies. J. Biochem. 2016, 159, 111-121. [CrossRef]

30. Turner, K.B.; Zabetakis, D.; Goldman, E.R.; Anderson, G.P. Enhanced stabilization of a stable single domain antibody for SEB toxin by random mutagenesis and stringent selection. Protein Eng. Des. Sel. 2014, 27, 89-95. [CrossRef]

31. Zabetakis, D.; Olson, M.A.; Anderson, G.P.; Legler, P.M.; Goldman, E.R. Evaluation of Disulfide Bond Position to Enhance the Thermal Stability of a Highly Stable Single Domain Antibody. PLoS ONE 2014, 9, e115405. [CrossRef] [PubMed] 
32. Zhu, G.; Jin, M.; Gui, W.; Guo, Y.; Jin, R.; Wang, C.; Liang, C.; Liu, Y.; Wang, T. Development of a direct competitive enzyme-linked immunoassay for carbofuran in vegetables. Food Chem. 2008, 107, 1737-1742. [CrossRef]

33. Moreno, M.; Abad, A.; Pelegrí, P.; Martínez, M.; Sáez, A.; Gamón, M.; Montoya, A. Validation of a Monoclonal Enzyme Immunoassay for the Determination of Carbofuran in Fruits and Vegetables. J. Agric. Food Chem. 2001, 49, 1713-1719. [CrossRef] [PubMed]

(C) 2019 by the authors. Licensee MDPI, Basel, Switzerland. This article is an open access article distributed under the terms and conditions of the Creative Commons Attribution (CC BY) license (http://creativecommons.org/licenses/by/4.0/). 